\title{
Suppression of Oral Carcinoma Oncogenic Activity by microRNA-203 via Down-regulation of SEMA6A
}

\author{
HYOUNG-SUP LIM ${ }^{1}$, CHUN SUNG KIM ${ }^{1}$, JAE-SUNG KIM ${ }^{1}$, SUN-KYOUNG YU ${ }^{1}$, DAE-SAN GO ${ }^{1}$, \\ SEUL AH LEE ${ }^{1}$, SUNG MIN MOON ${ }^{1}$, HONG SUNG CHUN ${ }^{2}$, SU GWAN KIM ${ }^{1}$ and DO KYUNG KIM ${ }^{1}$ \\ ${ }^{1}$ Oral Biology Research Institute, School of Dentistry, Chosun University, Gwangju, Republic of Korea; \\ ${ }^{2}$ Department of Biomedical Science, Chosun University, Gwangju, Republic of Korea
}

\begin{abstract}
Background/Aim: The purpose of this study was to elucidate the molecular mechanism underlying regulation of semaphorin-6A (SEMA6A) involving microRNA-203 (miR203) as a tumor suppressor in YD-38 human oral cancer cells. Materials and Methods: miRNA arrays, polymerase chain reaction analyses, MTT assays, immunoblotting, and luciferase assays were carried out in YD-38 cells. Results: MiRNA microarray results showed that expression of miR203 was significantly down-regulated in YD-38 cells compared to normal human oral keratinocytes. The viability of YD-38 cells was reduced by miR-203 in time- and dosedependent manners. Overexpression of miR-203 increased the nuclear condensation of YD-38 cells and activated the apoptotic signaling pathway by up-regulating pro-apoptotic factors, such as BCL-2-associated $X$ protein $(B A X)$ and $B C L$ 2 homologous antagonist killer (BAK), and the active forms of caspase-9, caspase-3, and poly-(ADP-ribose)-polymerase $(P A R P)$. Furthermore, target gene array analyses revealed that the expression of class 6 semaphorin A (SEMA6A) was down-regulated by miR-203 in YD-38 cells. Both the $m R N A$ and protein levels of SEMA6A were reduced in YD-38 cells transfected with miR-203. Luciferase activity assay confirmed that miR-203 directly targets the SEMA6A 3'untranslated region to suppress gene expression. Conclusion: Our results indicate that $\mathrm{miR}-203$ induces the apoptosis of $Y D-38$ human oral cancer cells by directly targeting SEMA6A, suggesting its potential application in anticancer therapeutics.

MicroRNAs (miRNAs) are endogenous 19-25 nucleotide
\end{abstract}

Correspondence to: Do Kyung Kim, Department of Oral Physiology, School of Dentistry, Chosun University, 309 Pilmundaero, Dong-gu, Gwangju 61452, Republic of Korea. Tel: +82 622306893, Fax: +82 622326896, e-mail:kdk@chosun.ac.kr

Key Words: miR-203, tumor suppressor, oral cancer cells, SEMA6A, apoptosis. non-coding sequences (1) and are important posttranscriptional, sequence-specific regulators of gene expression that act on the 3'-untranslated regions (UTR) of mRNA target genes, causing translation inhibition and mRNA degradation (2). miRNAs have been profiled according to their typical mechanism of transcriptional regulation in a variety of cells and cellular systems (1). They may regulate $>90 \%$ of human genes (3) and control various cellular biological processes such as cell development, proliferation and differentiation, and apoptosis (4). In addition, although a large number of recent studies have demonstrated alterations in miRNA function as oncogenes or suppressor genes and that their aberrant expression contributes to human diseases such as cancer, their biological functions and cellular mechanisms remain largely unknown (5).

Many studies have examined the biological functions of miRNA-203 (miR-203) as a tumor suppressor in carcinogenesis. Saini et al. reported that $m i R-203$ suppresses prostate cancer cell progression and metastasis by targeting a cohort of pro-metastatic genes (6). Jin et al. (7) and Wang et al. (8) reported that miR-203 inhibits cell proliferation and migration by targeting protein kinase $\mathrm{C}$-alpha $(P K C \alpha)$ or survivin expression in lung cancer cells $(7,8)$. In another study, Bueno et al. demonstrated that genetic and epigenetic silencing of $m i R$-203 enhanced expression of the oncogenes abelson murine leukemia viral oncogene homolog $1(A B L 1)$ and breakpoint cluster region protein $(B C R)-A B L 1$ in specific hematopoietic malignancies (9). In contrast, the antitumorigenic function and signaling pathway of $m i R-203$ in oral cancer cells remain unclear.

Semaphorins are secreted or transmembrane proteins initially identified based on their role in axon guidance and regulation of cell motility, immune response, cell differentiation, morphology, angiogenesis, and tumor progression (10). Semaphorins contain a conserved extracellular domain of $\sim 500$ amino acids (the Sema domain) that is shared with their receptors plexins (11). In the mammalian system, they are subdivided into five different 
subfamilies (semaphorins 3-7) based on specific structural properties (12). Emerging evidence suggests that the expression of specific semaphorins is important in tumor development or progression (12). However, some studies found that semaporins are overexpressed in cancer, whereas others are down-regulated (13-16).

The transmembrane protein SEMA6A, the first identified class 6 semaphorin (17), is a membrane-bound protein and functions as a guidance cue for nerve axons and migrating cells in the developing central nervous system 12). It was shown that SEMA6A regulates the formation of laminaspecific axon projections in the hippocampus (18), as well as formation of the cortical spinal tract (19). Class 6 semaphorins have also been implicated in cancer development (12). One study showed that in melanoma cells, depletion of SEMA6A alters the cytoskeleton, impairs anchorage-independent growth, and affects motility and invasive activities (20). In addition, SEMA6A mRNA expression was increased in several renal tumor tissue samples and renal cell carcinoma cell lines, whereas its recombinant soluble extracellular domain inhibited angiogenesis induced by growth factors and tumor cell lines $(10,21)$. However, the mechanism underlying SEMA6A regulation in cancer cells, including oral cancer cells, is largely unknown.

Here, we examined the biological function of $m i R-203$ as a tumor suppressor in YD-38 human oral cancer cells. Furthermore, the molecular mechanism underlying the $m i R$ 203-mediated effect on SEMA6A expression in YD-38 human oral cancer cells was investigated.

\section{Materials and Methods}

Materials. 3-[4,5-Dimethylthiazol-2-yl]-2,5-diphenyltetrazolium bromide (MTT) was purchased from Sigma Aldrich (St. Louis, MO, USA). Antibodies to cleaved caspase-3, cleaved caspase-9, cleaved poly (ADP-ribose) polymerase (PARP), BCL-2-associated X protein (BAX) and BCL-2 homologous antagonist killer (BAK), and $\beta$-actin were purchased from Cell Signaling Technology, Inc. (Danvers, MA, USA). All other analytical reagents purchased were of analytical grade.

Cell line and cell cultures. Normal human oral keratinocytes (NHOKs) were purchased from ScienCell Research Laboratories (Carlsbad, CA, USA) and maintained according to the manufacturer's instructions. The human oral cancer cell line derived YD-38 cells was provided by the Korean Cell Line Bank (Seoul, Korea) and cultured according to the supplier's instructions. Briefly, YD-38 cells were grown in RPMI-1640 containing 10\% fetal bovine serum. The cells were maintained as monolayers in plastic culture plates at $37^{\circ} \mathrm{C}$ in a humidified atmosphere containing $5 \% \mathrm{CO}_{2}$.

Plasmid construction. To induce overexpression of $m i R-203$, we generated a pSuper-miR-203 construct as previously described (22). To verify miR-203-induced SEMA6A gene expression using a luciferase assay, the 3'-UTR of SEMA6A containing the predicted target sites of $m i R-203$ was amplified from human genomic DNA by proofreading the Phusion High-Fidelity PCR master mix (New England BioLabs ${ }^{\circledR}$ Inc., Ipswich, MA, USA) with the following primers: SEMA6A-3'-UTR-F, 5'-CGAGCCCGGGACTCCCAGG GGGAGGGGGTCAGGT-3'; SEMA6A-3'-UTR-R, 5'-TCAGCG GCCGCTCGTTTTTTCCCTTTTTTTCT-3'. The amplified SEMA6A-3'-UTR, 2,997 bp in size, was digested with SmaI and NotI. The digested SEMA6A-3'-UTR was inserted into the multiple cloning regions downstream of the hRluc gene in psiCHECK ${ }^{\mathrm{TM}}-1$ (Promega, Madison, WI, USA). The clones were confirmed by sequencing.

Transfection and cell viability assay. The MTT assay was applied to estimate the effect of $m i R-203$ on YD-38 cell proliferation. The cells were plated at a density of $5 \times 10^{3}$ cells/well in 96-well plates and allowed to attach to the wells overnight. After incubation, the cultured cells were transfected with pSuper-miR-203 (Oligoengine, Seattle, WA, USA) at 2,20 , or $200 \mathrm{ng} / \mathrm{ml}$ for 24 or $48 \mathrm{~h}$ at $37^{\circ} \mathrm{C}$ in a dosedependency test using Lipofectamine ${ }^{\mathrm{TM}} 2000$ (Invitrogen, Carlsbad, CA, USA) according to the manufacturer's instructions. In addition, $200 \mathrm{ng} / \mathrm{ml}$ of pSuper-miR-203 was transfected into the YD-38 cells and incubated for 24 or $48 \mathrm{~h}$ as a time-dependency test. Next, the cells were incubated for an additional $4 \mathrm{~h}$ in $20 \mu \mathrm{lof} 5 \mathrm{mg} / \mathrm{ml}$ MTT. To dissolve the formazan crystals transformed from MTT, the cells were resuspended in $150 \mu \mathrm{l}$ dimethyl sulfoxide and the optical density (OD) of the solution was determined using a spectrometer at a wavelength of $495 \mathrm{~nm}$.

Affymetrix miRNA array and data pre-processing. Total RNAs from both YD-38 cells and NHOKs were isolated with a miRNeasy mini kit (Qiagen, Hilden, Germany) following the manufacturer's instructions. The miRNA array was scanned using an Affymetrix GeneChip Platform (Affymetrix, Santa Clara, CA, USA). Total RNA was subjected to a tailing reaction $\left(2.5 \mathrm{mM} \mathrm{MnCl}_{2}\right.$, ATP, and polyA polymerase; incubation for $15 \mathrm{~min}$ at $37^{\circ} \mathrm{C}$ ), followed by ligation of the biotinylated signal molecule to the target RNA sample and addition of stop solution. Each sample was hybridized to a GeneChipH miRNA Array at $48^{\circ} \mathrm{C}$ and $60 \mathrm{rpm}$ for $16 \mathrm{~h}$, washed, stained on a Fluidics Station 450, and scanned with a GeneChip $^{\circledR}$ Scanner3000 7G (Affymetrix). Image data were analyzed with miRNA QC Tool (ThermoFisher scientific, Waltham, MA, USA) software for quality control.

Identification of miR-203 target genes. DNA samples isolated from YD-38 cells overexpressing miR-203 were evaluated on a DMET microarray (Affymetrix) using DMET Plus Premier Pack kits according to the manufacturer's protocol. Hybridized DMET arrays were washed and stained in Affymetrix fluidic stations and scanned with the Affymetrix GeneChip ${ }^{\circledR}$ Scanner 3000 7G. Data were generated with Affymetrix GeneChip ${ }^{\circledR}$ Command console software and analyzed with DMET Console software.

Evaluation and quantification of apoptosis. To evaluate chromatic condensation as an apoptotic phenomenon in YD-38 cells transfected with $m i R-203$, cells were seeded at a density of $2 \times 10^{3}$ cells/well in a 4-well chamber slide and incubated overnight. Next, $200 \mathrm{ng} / \mathrm{ml}$ of pSuper-miR-203 was transfected into the cultured YD38 cells using Lipotectamine ${ }^{\mathrm{TM}} 2000$ for $48 \mathrm{~h}$. After incubation, the cells were fixed with $1 \%$ paraformaldehyde and washed three times with phosphate-buffered saline. For nuclear staining, YD-38 cells 
were incubated with 4'-,6'-diamidino-2-phenlyindole dihydrochloride (DAPI; Roche Diagnostics, Basel, Switzerland) for $15 \mathrm{~min}$. Apoptotic cells were quantified by assessing the characteristic nuclear changes of apoptosis using fluorescence microscopy (Eclipse TE200; Nikon Instruments, Tokyo, Japan).

Quantitative real-time polymerase chain reaction ( $q R T-P C R)$ and quantitative PCR ( $q P C R$ ). Total RNA, including mature miRNA, was isolated using an miRNeasy mini kit (Qiagen), and the RNA was quantified by spectrophotometry (NanoDrop 2000; Thermo Fisher Scientific, Inc., Waltham, MA, USA) according to the manufacturer's instructions. Reverse transcription of miRNA was performed using a miScript Reverse Transcription kit (Qiagen) with $1 \mu \mathrm{g}$ of total RNA. TaqMan miRNA assays kits (Life Technologies, Carlsbad, CA, USA) were used to examine miR-203 (5'GTGAAATGTTTAGGACCACTA-3') expression by qRT-PCR according to the manufacturer's instructions. The qRT-PCR results, which were recorded as threshold cycle numbers $(\mathrm{Ct})$, were normalized against glyceraldehyde 3-phosphate dehydrogenase $(G A P D H)$ (forward primer sequences: 5'-CTTTGGTATCGTGGAA GGACTC-3'; reverse primer sequences: 5'-AGTAGAGGCAGG GATGATGT-3') used as an internal control, and the comparative threshold cycle method $\left({ }^{\Delta \Delta} \mathrm{Ct}\right)$ was used to determine miRNA expression levels. Furthermore, the level of SEMA6A (forward primer sequences: 5'-TGCCCATATGCCAAACATGCC-3'; reverse primer sequences: 5'-TCTCCGTAATCCACGGCTTGAACA-3') induction was measured by PCR. The deviations of the samples were determined from four separate experiments.

For qPCR, total RNA was isolated from YD-38 cells using TRIzol reagent (Gibco BRL, Grand Island, NY, USA) according to the manufacturer's protocol. Reverse transcription was carried out with $1 \mu \mathrm{g}$ of total RNA and Moloney Murine Leukemia Virus reverse transcriptase (Promega, Madison, WI, USA). The expression levels of SEMA6A were measured by qPCR and visualized by DNA agarose gel electrophoresis. Differences in expression are presented as a histogram after densitometric analysis using a VersaDoc ${ }^{\mathrm{TM}}$ imaging system (Bio-Rad, Hercules, CA, USA). GAPDH was used as an internal standard.

Immunoblotting. To determine the levels of activated SEMA6A, cleaved caspase- 3 , cleaved caspase- 9 , cleaved-PARP, BAK, and BAX in YD-38 cells transfected with pSuper-miR-203, the proteins were extracted, electrophoresed by $10 \%$ sodium dodecyl sulfatepolyacrylamide gel electrophoresis, and transferred to polyvinylidene fluoride membranes for immunoblotting using primary antibodies against SEMA6A, cleaved caspase-3, cleaved caspase-9, cleaved PARP, BAK, BAX, and $\beta$-actin as previously described (23).

Luciferase assays. miR-203 and scrambled $m i R-203$ were purchased from Ambion (Austin, TX, USA). The $m i R-203$, scrambled $m i R$ 203, and psiCHECK-1-promoter-SEMA6A-3'-UTR were transfected into cultured YD-38 cells using Lipofectamine ${ }^{\mathrm{TM}} 2000$ (Invitrogen) according to the manufacturer's instructions. The experimental group of YD-38 cells was treated with $1 \mathrm{ng} / \mathrm{ml}$ miRNAs for 2 days Next, the cells were harvested and lysed for luciferase assays $48 \mathrm{~h}$ after transfection using the Dual Luciferase Reporter Assay System (Promega) according to the manufacturer's protocol. Renilla/firefly luciferase activity was calculated for each reaction.

Statistical analysis. All experiments were performed at least four times. The results are presented as the mean \pm SEM. Statistical significance was analyzed by using Student's $t$-test for two groups and one-way analysis of variance for multi-group comparisons. All statistical analyses were performed using SPSS version 12.0 (SPSS, Inc., Chicago, IL, USA). Differences with values of $p<0.05$ were considered significant.

\section{Results}

miR-203 expression was significantly down-regulated in $Y D$ 38 cells. To identify YD-38-related miRNAs, we performed a miRNA microarray on YD-38 and NHOK cells $(n=4$ per cell line) using an Affymetrix GeneChip and the data were analyzed, as described previously (24). miRNAs differentially expressed in YD-38 cells and NHOKs were identified (Figure 1A). We focused on miR-203 because its expression was significantly down-regulated by approximately 24-fold in YD-38 cells compared to NHOKs. The microRNA array results were verified by examining the expression pattern of $m i R-203$ by miRNA qRT-PCR using miRNA isolated from both YD-38 cells and NHOKs (Figure 1B). qRT-PCR analysis showed that $m i R-203$ expression was significantly down-regulated in YD-38 cells by up to $95 \%$ compared to NHOKs (Figure 1C).

Overexpression of miR-203 inhibits cell proliferation and induces apoptosis of YD-38 cells. To determine whether overexpression of $m i R-203$ affects the cell proliferation of YD-38 cells, $200 \mathrm{ng} / \mathrm{ml}$ of pSuper-miR-203 was transfected into YD-38 cells using Lipofectamine ${ }^{\mathrm{TM}} 2000$. After $48 \mathrm{~h}$, cell proliferation was assessed in an MTT assay. As shown in Figure 2A, up-regulation of $m i R-203$ did not alter the viability of NHOKs. In contrast, the proliferation of YD-38 cells transfected with $200 \mathrm{ng} / \mathrm{ml}$ of pSuper-miR-203 gradually decreased with time and was reduced by approximately $30 \%$ compared to cells treated with either the non-transfected or empty vector-only (Figure 2B). Moreover, the cell proliferation of YD-38 cells decreased with increasing concentrations of pSuper-miR-203, as shown in Figure 2C.

Cell morphology was also assessed by DAPI staining, which detects nuclear condensation. The number of cells with the typical morphology of apoptosis was increased when $m i R$-203 was overexpressed in YD-38 cells by at least 3.5-fold more than both the un-transfected and empty vector cells, as shown in Figure 2D. Otherwise, cells remained intact with no chromatin condensation in the untransfected control nor in YD-38 cells transfected with the empty vector.

Next, in order to evaluate the apoptotic signaling pathways involved in apoptosis induced in miR-203overexpressing YD-38 cells, we measured the expression of apoptotic signaling pathway-related proteins by western blotting in YD-38 cells treated with $200 \mathrm{ng} / \mathrm{ml}$ of pSuper$m i R-203$ for $48 \mathrm{~h}$. Expression of the pro-apoptotic factors BAX, BAK, and cleaved caspase-9 was significantly 
A

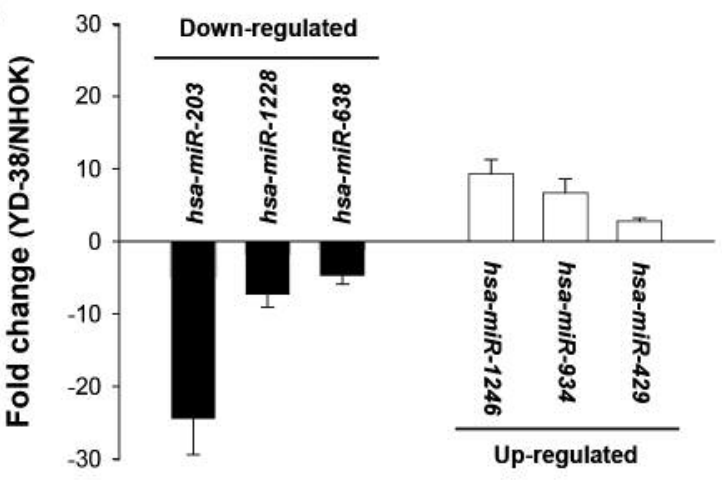

B

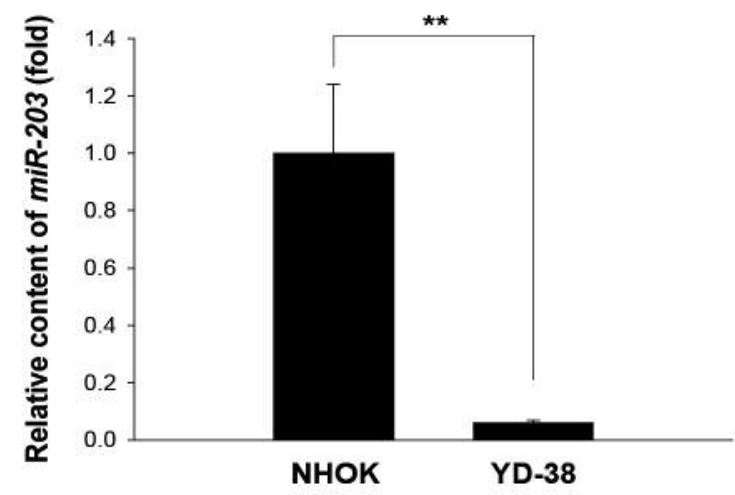

C

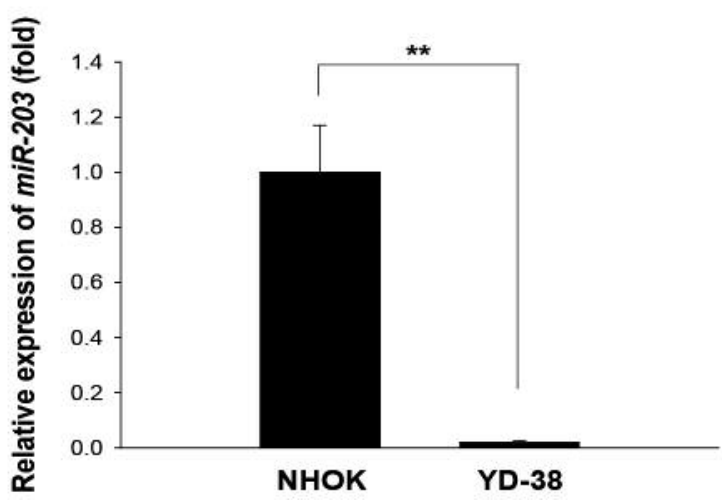

Figure 1. Expression of miR-203 is down-regulated in YD-38 cells. A: Total RNA from both YD-38 cells and NHOKs was isolated, scanned using an Affymetrix GeneChip Platform, stained on Fluidics Station 450 , and scanned on a GeneChip ${ }^{\circledR}$ Scanner 30007 G. Each absolute fold change value represents the mean of four independent experiments. $B$ : The relative expression of miR-203 in YD-38 cells and NHOKs was assessed by quantitative real time-polymerase chain reaction, as described in the Materials and Methods. C: The relative expression of miR-203 in YD-38 cells and NHOKs was assessed by quantitative polymerase chain reaction is shown as a histogram after densitometric analysis. Each data point represents the mean \pm SEM of at least four independent experiments. ${ }^{*} p<0.01 \mathrm{vs}$. control. increased when miR-203 was overexpressed (Figure 2E). Therefore, we analyzed the expression of cleaved caspase- 3 and its downstream target molecule PARP. As shown in Figure 2E, cleaved caspase-3 was significantly upregulated in YD-38 cells treated with $m i R-203$. Subsequently, the level of cleaved PARP, which functions downstream of caspase-3 $(25,26)$, was significantly increased by $m i R-203$ treatment in YD-38 cells (Figure 2E). Taken together, these data suggested that overexpression of $m i R-203$ inhibited cell proliferation and induced the apoptosis of YD-38 cells.

Overexpression of miR-203 regulates the expression of SEMA6A in YD-38 cells. To identify miR-203 target genes in YD-38 cells, a target gene array was performed using DMET Plus Premier Pack kits (Affymetrix) according to the manufacturer's protocol. As shown in Figure 3, miR-203 overexpression induced down-regulation of SEMA6A, ATPbinding cassette sub-family $\mathrm{E}$ member 1 ( $A B C E 1)$, and myeloid/lymphoid or mixed-lineage leukemia translocated to 4 (MLLT4), whereas interleukin 24 (IL24), sel-1 suppressor of lin-12-like (SEL1L), and ADAM metallopeptidase with thrombospondin type 1 motif 6 (ADAMTS6) were significantly up-regulated by miR-203 overexpression in YD38 cells. We are currently evaluating alterations in the expression of other genes associated with miR-203. The mRNA expression of SEMA6A is elevated in several renal tumor tissue samples, suggesting that SEMA6A is a promising biomarker for the detection and diagnosis of cancer $(10,21)$. Therefore, we hypothesized that overexpression of $m i R-203$ induces apoptosis via down-regulation of SEMA6A in YD-38 cells. To further confirm that miR-203 inhibits SEMA6A expression in YD-38 cells, pSuper-miR-203 constructs were transfected into YD-38 cells and the mRNA and protein levels of SEMA6A were analyzed.

As shown in Figure 4A and B, both qPCR and qRT-PCR showed that SEMA6A expression was significantly reduced, by approximately $40 \%$, in YD-38 cells transfected with 200 $\mathrm{ng} / \mathrm{ml}$ of pSuper-miR-203 compared to in empty vector-only cells.

In addition, SEMA6A protein expression was notably reduced by $m i R-203$, as shown in Figure $4 \mathrm{C}$. A histogram of densitometric analysis normalized to expression of $\beta$-actin showed that the level of SEMA6A protein expression was reduced compared to that in empty vector-transfected cells. Together, these results suggest that $m i R-203$ reduced the expression of SEMA6A, indicating that SEMA6A is a downstream target gene in YD-38 cells.

SEMA6A is directly targeted by miR-203. To determine the mechanism of miR-203-mediated down-regulation of SEMA6A in YD-38 cells, we performed target gene scanning using TargetScan (http://www.targetscan.org/) and miRBase (http://www.mirbase.org/) and found that SEMA6A was a 


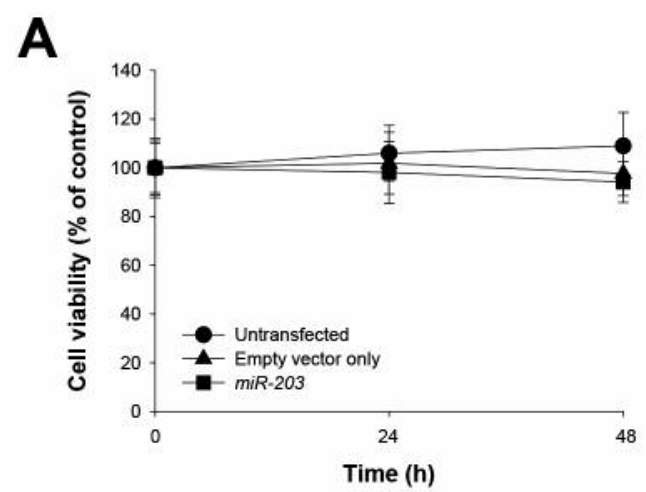

B

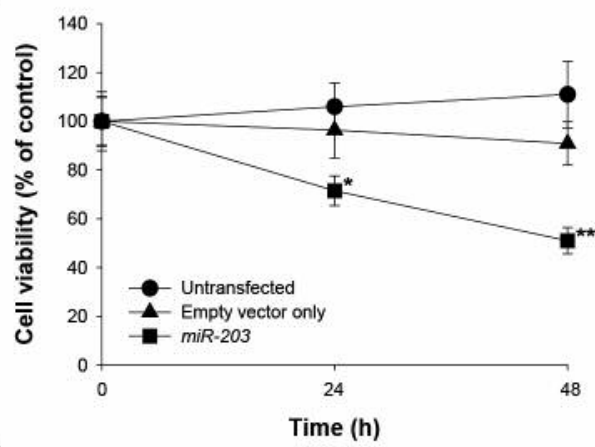

C

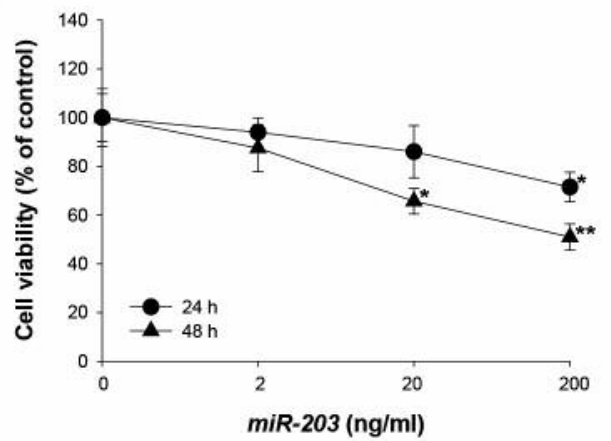

D
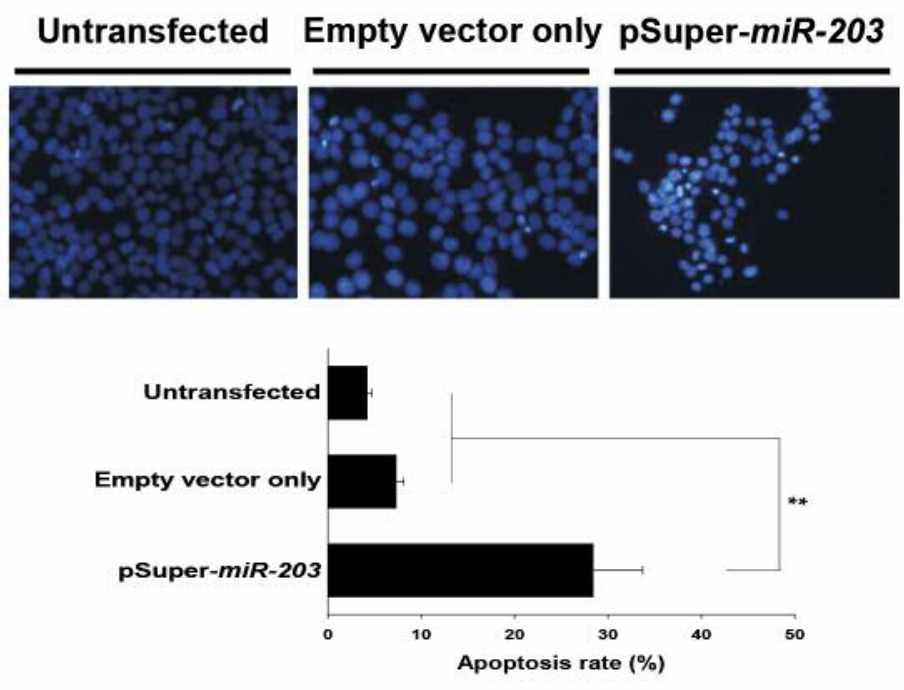

$\mathbf{E}$

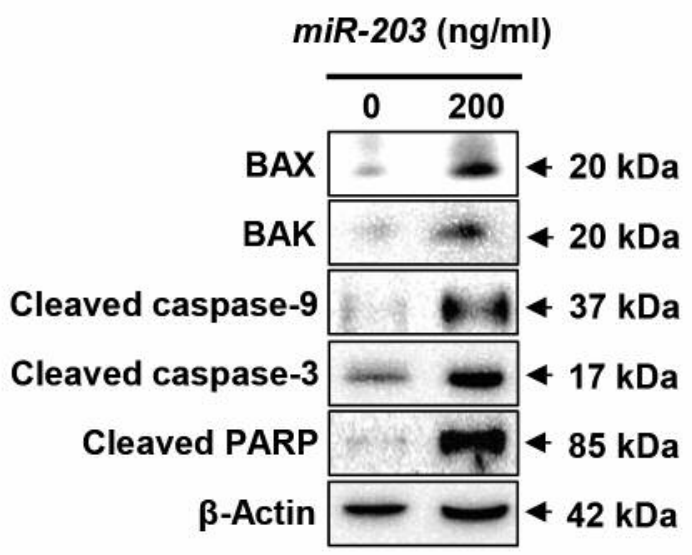

Figure 2. Overexpression of miR-203 increases cytotoxicity via apoptotic cell death in YD-38 cells. Cell viability of NHOKs (A) and YD-38 cells $(B, C)$ was measured after miR-203 transfection over time and at different concentrations. Cell cytotoxicity was assessed by MTT assay after miR203 transfection into YD-38 cells. D: Nuclear morphology was observed using 4',6-diamidino-2-phenylindole (DAPI) staining after transfection with $200 \mathrm{ng} / \mathrm{ml}$ of pSuper-miR-203. The percentage of apoptotic cells was calculated as the ratio of apoptotic cells to total cells. E: Overexpression of miR-203 induced apoptosis of YD-38 cells. YD-38 cells were transfected with $200 \mathrm{ng} / \mathrm{ml}$ of pSuper-miR-203. Cell lysate was prepared and analyzed by immunoblotting as described in the Materials and Methods. ${ }^{*} p<0.05$ vs. control and ${ }^{* *} p<0.01$ vs. control.

predicted target gene. Furthermore, SEMA6A contains a potential complementary binding sequence located from nucleotide 1,155 to 1,161 in its 3'-UTR, indicating that $m i R$ 203 can directly target this site. Therefore, we cloned 2,997 base pairs (full-length) of the SEMA6A 3'-UTR into the firefly luciferase based-psiCHECK-1 vector. In addition, a psiCHECK-1-empty vector was transfected into YD-38 cells to assess the basal level of luciferase activity (Figure 5A). As shown in Figure 5B, the relative luciferase activity of the reporter containing the 3'-UTR of SEMA6A was notably reduced in miR-203-transfected cells by approximately 1.9fold compared to control in YD-38 cells. In contrast, the psiCHECK-1-empty vector plus pSuper-miR-203 and psiCHECK-1-SEMA6A plus pSuper-empty vector led to similar basal levels of luciferase activity. These results suggest that SEMA6A is a novel and specific target gene of $m i R-203$ and $m i R-203$ may regulate SEMA6A expression in YD-38 cells. 


\section{Discussion}

In the present study of the pathophysiological role of miR203 in cancer cells, we demonstrated that the expression of $m i R-203$ was most significantly down-regulated in YD-38 cells compared to that in NHOKs (normal tissues) in the present study (Figure 1). Therefore, these data suggest that $m i R-203$ may be clinically useful for developing prognostic biomarkers. These data also suggest that down-regulation of $m i R-203$ is closely associated with oral cancer progression.

Recently, miRNA research associated with cancer therapies has suggested that overexpression of tumor suppressor miRNAs such as miR-124 in gastric cancer (27), $m i R-494-3 p$ in prostate cancer (28), miR-23a/b in lymphoma (29), and miR-205 in oral cancer (30) can inhibit proliferation and induce apoptosis of cancer cells. More recently, Tian et al. reported that overexpression of $m i R-203$ suppressed proliferation and induced apoptosis of laryngeal squamous cell carcinoma (31). Therefore, based on our results and those of previous studies, we hypothesized that overexpression of $m i R-203$ could induce apoptosis of YD-38 cells by altering cellular responses. As shown in Figure 2, cell viability gradually decreased in YD-38 cells transfected with $m i R$-203 in both time- and dose-dependent manners. Furthermore, overexpression of $m i R-203$ increased nuclear condensation in YD-38 cells, as shown by DAPI staining (Figure 2D). Moreover, miR-203 up-regulated or activated the pro-apoptotic factors, BAX, BAK, and cleaved caspase$9(25,26)$, as shown in Figure 2E. The levels of cleaved caspase-3 and cleaved PARP were significantly increased in YD-38 cells transfected with $m i R-203$ (Figure 2E). Finally, as a typical phenomenon of apoptosis, activated PARP induced DNA fragmentation via single-strand DNA breakage $(25,26)$ in the nucleus of YD-38 cells. These data suggest that $m i R-203$ led to apoptotic cell death in YD-38 cells. However, the complete mechanisms of $m i R$-203-induced apoptosis in YD-38 cells remain unclear. Further studies are needed to determine these cellular and molecular mechanisms.

miRNAs are thought to elicit their effects by base-pairing complementation between the seed sequence of miRNAs and 3'-UTR of their target mRNAs, which is a key determinant of miRNA-target recognition (32). Therefore, we used a $m i R-203$ target gene array to explore the molecular biological mechanism of $m i R$-203-induced apoptosis in YD38 cells. The results of the $m i R-203$ target gene array in YD38 cells revealed that overexpression of $m i R$-203 altered the expression patterns of some oncogenes. Although miR-203 changed the expression of some tumor-suppressor genes, we focused on down-regulated oncogenes in YD-38 cells transfected with miR-203 because miRNAs typically suppress protein expression by affecting mRNA translation

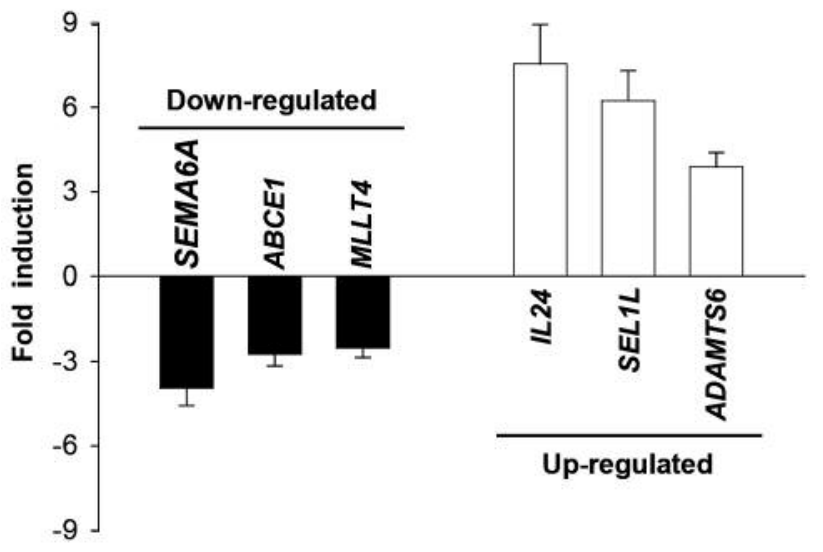

Figure 3. Semaphorin 6A (SEMA6A) is a target gene of miR-203 in YD38 cells. DNA samples isolated from YD-38 cells with overexpression of miR-203 were run on a DMET microarray, stained in the Affymetrix fluidic stations, and scanned with Affymetrix GeneChip ${ }^{\circledR}$ Scanner 3000 7G. Data were generated with Affymetrix GeneChip ${ }^{\circledR}$ Command console software and analyzed with the DMET Console software. Each absolute fold-change value represents the mean of four independent experiments. ABCE1: ATP-binding cassette sub-family E member 1; MLLT4: myeloid/lymphoid or mixed-lineage leukemia translocated to 4; IL24: interleukin 24; SEL1L: sel-1 suppressor of lin-12-like; ADAMTS6: ADAM metallopeptidase with thrombospondin type 1 motif 6.

or stability through interactions with the 3'-UTR of their target mRNAs (32). As shown in Figure 3, SEMA6A, $A B C E 1$, and $M L L T 4$ were significantly down-regulated in YD-38 cells transfected with $m i R-203$, whereas $I L 24$, SELIL, and ADAMTS6 were significantly up-regulated. $A B C E 1$ plays an essential role in lung cancer progression and metastasis (33) and MLLT4 regulates cancer cell migration in colorectal carcinogenesis (34). Additionally, IL24 functions as a tumor suppressor in breast cancer (35), and SELIL also has a tumor-suppressive role in breast cancer (36). Furthermore, ADAMTS6 suppresses tumorigenesis by inhibiting cell migration and invasion in breast cancer (37). However, their oncogenic or tumor-suppressive activities remain largely unclear in different types of cancer. Although we are still conducting functional studies for both ABCE1 and MLLT4 in YD-38 cells, the expression of SEMA6A was most significantly down-regulated by $m i R-203$ in YD-38 cells (Figure 3).

Semaphorins comprise a large family of conserved glycoproteins that regulate cell motility, immune response, cell differentiation, morphology, angiogenesis, and tumor progression (12). Additionally, semaphorins and their receptors are involved in multiple functions during development and in adult organisms, particularly in the nervous system, immune system, and various pathological conditions (38). A recent study observed miRNA-mediated 

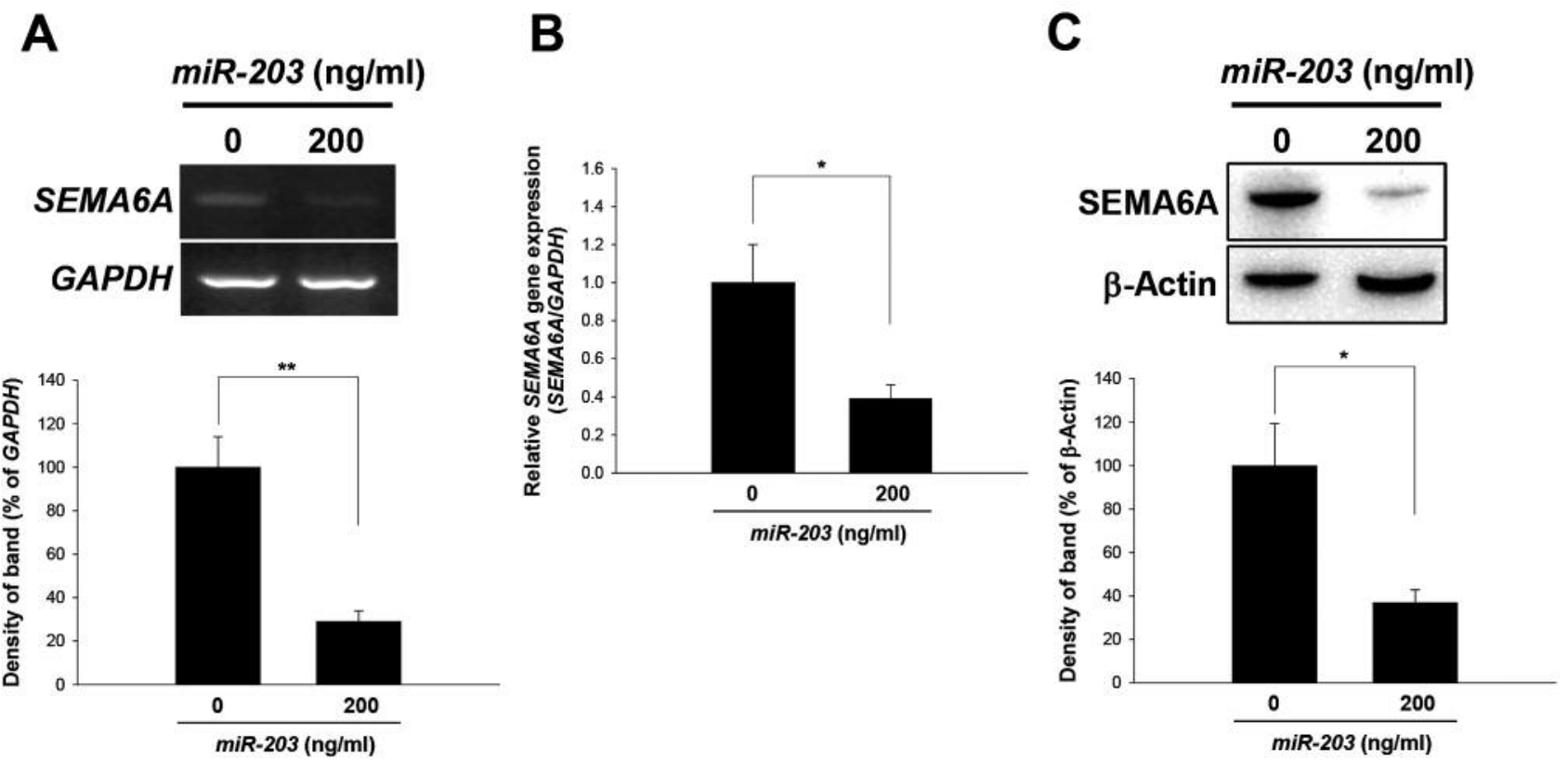

Figure 4. Overexpression of miR-203 reduces expression of the oncogenic gene semaphorin 6A (SEMA6A) in YD-38 cells. A; The expression of SEMA6A was measured by quantitative polymerase chain reaction (PCR) after miR-203 transfection. The amplified PCR products of SEMA6A were electrophoresed on agarose gels and the data presented as a histogram after densitometric analysis. B: The expression of SEMA6A was assessed by quantitative realtime PCR after miR-203 transfection into YD-38 cells. C: SEMA6A protein expression was quantified by western blotting using SEMA6A-specific antibody. Each data point represents the mean \pm SEM of at least four independent experiments. ${ }^{*} p<0.05$ vs. control and $* * p<0.01 v s$. control.

regulation of SEMA6A. Wolter et al. reported that SEMA6A up-regulation facilitated by miR-346 silencing may promote glioma growth (39). However, the mechanism underlying SEMA6A regulation related to miRNAs in cancer cells is unclear. In the present study and based on the results of previous studies $(10,21,39)$, we hypothesized that $m i R$-203-induced apoptosis of YD-38 cells is related to the suppression of SEMA6A. As shown in Figure 4, both mRNA induction and protein expression of SEMA6A were significantly suppressed by miR-203 transfection in YD-38 cells. These data suggest that SEMA6A is indeed a target oncogene of $m i R-203$ in YD38 cells.

However, miRNAs are thought to elicit their effects by silencing the expression of their target genes by directly interacting with their own regulatory region, such as the promoter (40) or 3'-UTR (32). Therefore, to identify the $m i R-203$ binding site in the SEMA6A gene, we performed target gene scanning and identified potential complementary binding sequences from positions 1,155 to 1,161 in its 3'-UTR as shown in Figure 5A. Next, to verify whether miR-203 can suppress the expression of SEMA6A in YD-38 cells, we generated the psiCHECK-1-SEMA6A construct, which contained potential complementary binding sequences for miR-203 in the 3'-UTR of SEMA6A. The miR-203 directly targets the 3'-UTR of SEMA6A, as its overexpression suppressed luciferase activity (Figure 5B). In contrast, the overexpression of mimic miR-203 did not affect $S E M A 6 A$ expression. These results suggest that miR-203 down-regulates SEMA6A directly via targeting of its 3'-UTR.

In conclusion, we found that $m i R-203$ functions as a tumor suppressor associated with suppression of SEMA6A in YD38 human oral cancer cells. Further analyses of the mechanism underlying the regulation of cancer progression by $m i R-203$ will contribute to the development of new oral cancer treatments and provide a new marker for the diagnosis of cancer.

\section{Conflicts of Interest}

None of the Authors have any conflict of interest in regard to this study.

\section{Acknowledgements}

This research was supported by Basic Science Research Program through the National Research Foundation of Korea (NRF) funded by the Ministry of Education (No. 2016R1D1A1A09916949). 


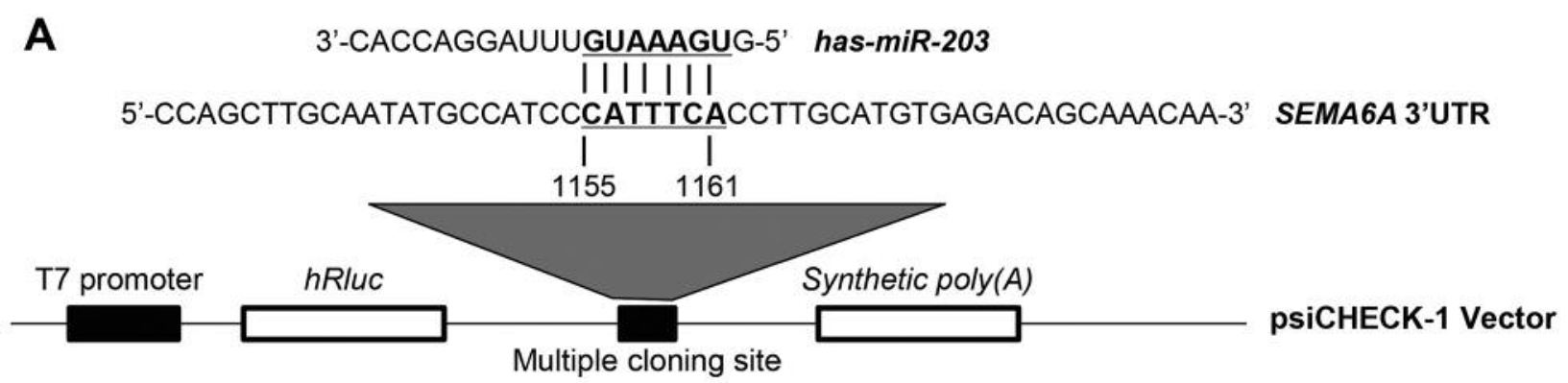

B

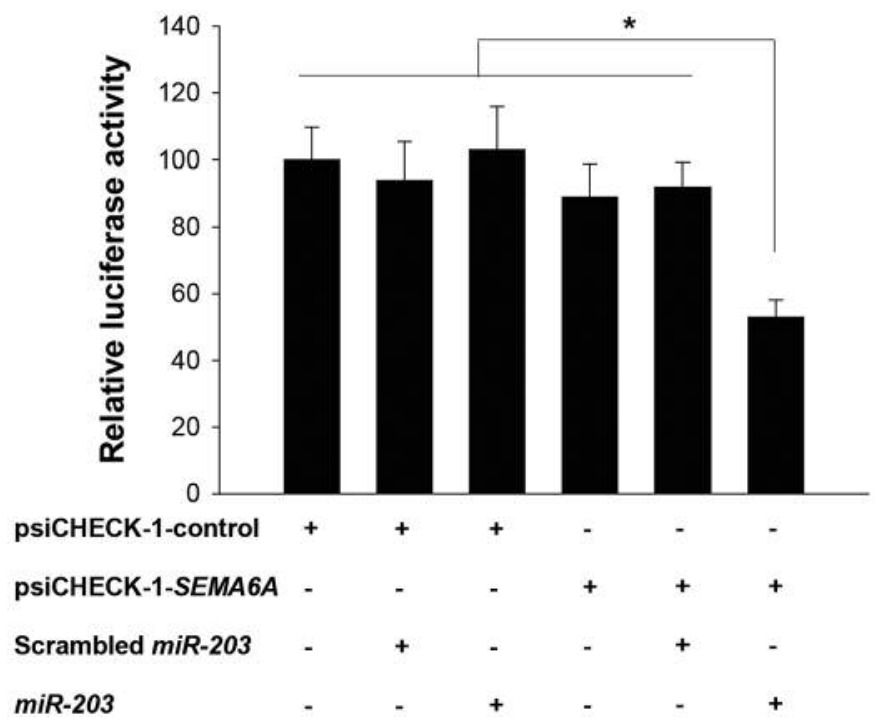

Figure 5. Semaphorin 6A (SEMA6A) is a direct target of miR-203 in YD-38 cells. A: The sequence of the miR-203 target sites on the SEMA6A-3'UTR. B: The luciferase activity of the SEMA6A promoter against miR-203. psiCHECK-2-SEMA6A was cloned as described in the Materials and Methods. Luciferase activity was normalized to total protein. Each data point represents the mean \pm SEM of at least four independent experiments. $* p<0.05$ vs. control.

\section{References}

1 Bonnet E, Wuyts J, Rouze P and Van de Peer Y: Evidence that microRNA precursors, unlike other non-coding RNAs, have lower folding free energies than random sequences. Bioinformatics 20: 2911-2917, 2004.

2 Valencia-Sanchez MA, Liu J, Hannon GJ and Parker R: Control of translation and mRNA degradation by miRNAs and siRNAs. Genes Dev 20: 515-524, 2006.

3 Miranda KC, Huynh T, Tay Y, Ang YS, Tam WL, Thomson AM, Lim B and Rigoutsos I: A pattern-based method for the identification of microRNA binding sites and their corresponding heteroduplexes. Cell 126: 1203-1217, 2006.

4 Chitwood DH and Timmermans MC: Small RNAs are on the move. Nature 467: 415-419, 2010.

5 Calin GA and Croce CM: MicroRNA signatures in human cancers. Nat Rev Cancer 6: 857-866, 2006.

6 Saini S, Majid S, Yamamura S, Tabatabai L, Suh SO, Shahryari V, Chen Y, Deng G, Tanaka Y and Dahiya R: Regulatory role of mir-203 in prostate cancer progression and metastasis. Clin Cancer Res 17: 5287-5298, 2011.
7 Jin J, Deng J, Wang F, Xia X, Qiu T, Lu W, Li X, Zhang H, Gu $\mathrm{X}$, Liu Y, Cao W and Shao W: The expression and function of microRNA-203 in lung cancer. Tumour Biol 34: 349-357, 2013.

8 Wang C, Wang X, Liang H, Wang T, Yan X, Cao M, Wang N, Zhang S, Zen K, Zhang $\mathrm{C}$ and Chen X: $m i R-203$ inhibits cell proliferation and migration of lung cancer cells by targeting PKCalpha. PLoS One 8: e73985, 2013.

9 Bueno MJ, Perez de Castro I, Gomez de Cedron M, Santos J, Calin GA, Cigudosa JC, Croce CM, Fernandez-Piqueras J and Malumbres M: Genetic and epigenetic silencing of microRNA203 enhances $A B L 1$ and $B C R-A B L 1$ oncogene expression. Cancer Cell 13: 496-506, 2008.

10 Prislei S, Mozzetti S, Filippetti F, De Donato M, Raspaglio G, Cicchillitti L, Scambia G and Ferlini C: From plasma membrane to cytoskeleton: a novel function for semaphorin 6A. Mol Cancer Ther 7: 233-241, 2008.

11 Kruger RP, Aurandt J and Guan KL: Semaphorins command cells to move. Nat Rev Mol Cell Biol 6: 789-800, 2005.

12 Zhao J, Tang H, Zhao H, Che W, Zhang L and Liang P: SEMA6A is a prognostic biomarker in glioblastoma. Tumour Biol 36: 8333-8340, 2015. 
13 Martin-Satue $\mathrm{M}$ and Blanco J: Identification of semaphorin E gene expression in metastatic human lung adenocarcinoma cells by mRNA differential display. J Surg Oncol 72: 18-23, 1999.

14 Deaglio S, Vaisitti T, Bergui L, Bonello L, Horenstein AL, Tamagnone L, Boumsell L and Malavasi F: CD38 and CD100 lead a network of surface receptors relaying positive signals for B-CLL growth and survival. Blood 105: 3042-3050, 2005.

15 Hirota E, Yan L, Tsunoda T, Ashida S, Fujime M, Shuin T, Miki T, Nakamura Y and Katagiri T: Genome-wide gene expression profiles of clear cell renal cell carcinoma: identification of molecular targets for treatment of renal cell carcinoma. Int $\mathrm{J}$ Oncol 29: 799-827, 2006.

$16 \mathrm{Hu}$ B, Guo P, Bar-Joseph I, Imanishi Y, Jarzynka MJ, Bogler O, Mikkelsen T, Hirose T, Nishikawa R and Cheng SY: Neuropilin1 promotes human glioma progression through potentiating the activity of the HGF/SF autocrine pathway. Oncogene 26: 55775586, 2007.

17 Zhou L, White FA, Lentz SI, Wright DE, Fisher DA and Snider WD: Cloning and expression of a novel murine semaphorin with structural similarity to insect semaphorin I. Mol Cell Neurosci 9: 26-41, 1997.

18 Suto F, Tsuboi M, Kamiya H, Mizuno H, Kiyama Y, Komai S, Shimizu M, Sanbo M, Yagi T, Hiromi Y, Chédotal A, Mitchell $\mathrm{KJ}$, Manabe $\mathrm{T}$ and Fujisawa $\mathrm{H}$ : Interactions between plexin-A2, plexin-A4, and semaphorin 6A control lamina-restricted projection of hippocampal mossy fibers. Neuron 53: 535-547, 2007.

19 Runker AE, Little GE, Suto F, Fujisawa H and Mitchell KJ: Semaphorin-6A controls guidance of corticospinal tract axons at multiple choice points. Neural Dev 3: 34, 2008.

20 Loria R, Bon G, Perotti V, Gallo E, Bersani I, Baldassari P, Porru M, Leonetti C, Di Carlo S, Visca P, Brizzi MF, Anichini A, Mortarini R and Falcioni R: SEM6A and MICAL1 control cell growth and survival of BRAFV600E human melanoma cells. Oncotarget 6: 2779-2793, 2015.

21 Dhanabal M, Wu F, Alvarez E, McQueeney KD, Jeffers M, MacDougall J, Boldog FL, Hackett C, Shenoy S, Khramtsov N, Weiner J, Lichenstein HS and LaRochelle WJ: Recombinant semaphorin 6A-1 ectodomain inhibits in vivo growth factor and tumor cell line-induced angiogenesis. Cancer Biol Ther 4: 659$668,2005$.

22 Lee SA, Kim JS, Park SY, Kim HJ, Yu SK, Kim CS, Chun HS, Kim J, Park JT, Go D and Kim DK: miR-203 down-regulates YES-1 and suppresses oncogenic activity in human oral cancer cells. J Biosci Bioeng 120: 351-358, 2015.

23 Yun S, Han YS, Lee JH, Kim S and Lee SH: Enhanced susceptibility to 5-fluorouracil in human colon cancer cells by silencing of GRP78. Anticancer Res 37: 2975-2984, 2017.

24 Choi HK, Kim DH, Kim JW, Ngadiran S, Sarmidi MR and Park CS: Labisia pumila extract protects skin cells from photoaging caused by UVB irradiation. J Biosci Bioeng 109: 291-296, 2010

25 Seo YS, Yim MJ, Kim BH, Kang KR, Lee SY, Oh JS, You JS, Kim SG, Yu SJ, Lee GJ, Kim DK, Kim CS, Kim JS and Kim JS: Berberine-induced anticancer activities in FaDu head and neck squamous cell carcinoma cells. Oncol Rep 34: 3025-3034, 2015.

26 Yu CS, Huang AC, Lai KC, Huang YP, Lin MW, Yang JS and Chung JG: Diallyl trisulfide induces apoptosis in human primary colorectal cancer cells. Oncol Rep 28: 949-954, 2012.

27 Xie L, Zhang Z, Tan Z, He R, Zeng X, Xie Y, Li S, Tang G, Tang $\mathrm{H}$ and $\mathrm{He} \mathrm{X}$ : MicroRNA-124 inhibits proliferation and induces apoptosis by directly repressing EZH2 in gastric cancer. Mol Cell Biochem 392: 153-159, 2014.

28 Shen PF, Chen XQ, Liao YC, Chen N, Zhou Q, Wei Q, Li X, Wang $\mathrm{J}$ and Zeng H: MicroRNA-494-3p targets CXCR4 to suppress the proliferation, invasion, and migration of prostate cancer. Prostate 74: 756-767, 2014.

29 Li B, Sun M, Gao F, Liu W, Yang Y, Liu H, Cheng Y, Liu C and Cai J: Up-regulated expression of $m i R-23 a / b$ targeted the proapoptotic FAS in radiation-induced thymic lymphoma. Cell Physiol Biochem 32: 1729-1740, 2013.

30 Kim JS, Yu SK, Lee MH, Park MG, Park E, Kim SG, Lee SY, Kim CS, Kim HJ, Chun HS, Chun SW and Kim DK: MicroRNA205 directly regulates the tumor suppressor, interleukin-24, in human KB oral cancer cells. Mol Cells 35: 17-24, 2013.

31 Tian L, Li M, Ge J, Guo Y, Sun Y, Liu M and Xiao H: miR-203 is down-regulated in laryngeal squamous cell carcinoma and can suppress proliferation and induce apoptosis of tumours. Tumour Biol 35: 5953-5963, 2014.

32 Nahvi A, Shoemaker CJ and Green R: An expanded seed sequence definition accounts for full regulation of the hid 3' UTR by bantam miRNA. RNA 15: 814-822, 2009.

33 Tian Y, Tian X, Han X, Chen Y, Song CY, Jiang WJ and Tian DL: ABCE1 plays an essential role in lung cancer progression and metastasis. Tumour Biol 37: 8375-8382, 2016.

34 Pichler M, Stiegelbauer V, Vychytilova-Faltejskova P, Ivan C, Ling H, Winter E, Zhang X, Goblirsch M, Wulf-Goldenberg A, Ohtsuka M, Haybaeck J, Svoboda M, Okugawa Y, Gerger A, Hoefler G, Goel A, Slaby O and Calin GA: Genome-wide miRNA analysis identifies $m i R-188-3 p$ as a novel prognostic marker and molecular factor involved in colorectal carcinogenesis. Clin Cancer Res 23: 1323-1333, 2017.

35 Menezes ME, Shen XN, Das SK, Emdad L, Guo C, Yuan F, Li YJ, Archer MC, Zacksenhaus E, Windle JJ, Subler MA, BenDavid Y, Sarkar D, Wang XY and Fisher PB: MDA-7/IL-24 functions as a tumor suppressor gene in vivo in transgenic mouse models of breast cancer. Oncotarget 6: 36928-36942, 2015.

36 Liu Q, Chen J, Wang J, Amos C, Killary AM, Sen S, Wei C and Frazier ML: Putative tumor suppressor gene SEL1L was downregulated by aberrantly up-regulated hsa-mir-155 in human pancreatic ductal adenocarcinoma. Mol Carcinog 53: 711-721, 2014.

37 Xie Y, Gou Q, Xie K, Wang Z, Wang Y and Zheng H: ADAMTS6 suppresses tumor progression via the ERK signaling pathway and serves as a prognostic marker in human breast cancer. Oncotarget 7: 61273-61283, 2016.

38 Kumanogoh A and Kikutani H: Immunological functions of the neuropilins and plexins as receptors for semaphorins. Nat Rev Immunol 13: 802-814, 2013.

39 Wolter M, Werner T, Malzkorn B and Reifenberger G: Role of microRNAs Located on Chromosome Arm 10q in Malignant Gliomas. Brain Pathol 26: 344-358, 2016.

40 Fujita S and Iba H: Putative promoter regions of miRNA genes involved in evolutionarily conserved regulatory systems among vertebrates. Bioinformatics 24: 303-308, 2008.

Received August 11, 2017

Revised September 1, 2017

Accepted September 6, 2017 